\title{
EXTERNALLY POWERED SPLINTS IN THE TREATMENT OF QUADRIPLEGICS
}

\author{
A. B. Kinnier Wilson, M.A., M.B., B.Chir., M.R.C.P. \\ Scientific Staff, Medical Research Council Centre for \\ Muscle Substitutes, West Hendon Hospital
}

IT is quite well known that artificial arms moved by a power source external to the patient's body are being used nowadays, especially for the treatment of thalidomideinduced deformities. Under the influence of this tragedy these devices are being steadily made more suited to their problems and their design and reliability are now reaching a high standard.

It is not so well known that externally powered splints for wheelchair patients with flaccid paralysis have also been developed (Nickel, 1964; Spencer, Engen \& Geddes, I964) and indeed for ambulant patients also (Kinnier Wilson, I962, I965). Recent improvements in the splinting systems have improved the performance of these devices to such an extent that their use to assist in the performance of the upper limbs of tetraplegics is well worth considering, particularly for those in whom fingertip sensation is preserved.

This paper is concerned not with the exposition of a single tried system but with the description of current techniques and in particular of several powered joints which might prove of value. The majority of these are gas-powered, using carbon dioxide at about five atmospheres from a liquefied source in a small bottle to drive very light-weight actuators. They are easily controlled by a suitable valve or valves of which there are several types now available. Some of the splint designs worked out for pneumatics are also beginning to be driven electrically, which for the present purpose might be more convenient since recharging of batteries is so much easier than refilling gas bottles: in many cases the splint would be mounted on the chair, bed or on a stand, in such a way as to keep the weight of the electric motors off the patient.

\section{SPLINT DESIGN}

A powered splint system may be considered in two parts, that which locates or moves the wrist and hand in space, and the prehension unit, comprising the wrist turning and finger closing mechanisms.

\section{The Shoulder Joint}

The first and probably most widely used device to give mobility of the arm from the shoulder is the ball race feeder (B.R.F.) or jointed arm support (Nickel, I964). This consists of a forearm gutter pivoted freely on a jointed horizontal bar. The proximal joint of this bar connects the bar with the upright of the wheelchair back and forms the shoulder surrogate. At the distal end of the first bar there is a second, corresponding to the elbow joint. Both these joints were originally formed 
with ball races and could be moved with little effort by the patient. The forearm gutter is mounted on the distal end of the second bar. Nickel and his co-workers at Rancho los Amigos have since motorised these joints in several ways, firstly by pneumatic motors, and now recently by an electric system. At Houston, Texas, Engen has used a somewhat different design employing a parallelogram layout, working more in the vertical plane, to lift the elbow forward and up.

\section{The Elbow}

Engen's parallelogram can be jointed to a powered elbow system by which the forearm is also lifted, rather than moved medially as in the Ball Race Feeder method, because the arm is held at a different angle and so therefore is the axis of the elbow joint. In the B.R.F. method the wrist is elevated by tilting the forearm gutter; as the elbow drops the wrist rises. A Hendon pneumatic version of this uses piston/cylinder actuators; Engen uses McKibben 'artificial muscles' as did Nickel (braided rubber tubes which when inflated expand sideways and shorten). Also in the field of elbow benders are splints for ambulant patients. The single iron motorised splint (Kinnier Wilson, 1962) and the inner arm splint/motor have proved valuable and are now being combined with the axillary splint developed in cooperation with Hendon by Redhead of Roehampton.

Powered wrist rotation is used at Rancho los Amigos with a separate motor (since their devices are all attached to the wheelchair, weight is of little importance). A wrist rotator mechanically coupled to the elbow joint to give a 'pick-up' position of the hand with thumb and forefinger downwards when the arm is extended below $90^{\circ}$, and a pronation movement as the elbow is bent has been developed at Hendon and shows promise.

\section{Grasp}

There are many systems for doing this which are currently being studied at Hendon, particularly with a view to making them lighter and less obtrusive. Particularly interesting is the diamond-link pinch grip, which can be employed in two different layouts. When two opposite corners of a diamond are approximated the axes of the remaining two joints rotate towards each other, and from this movement a pinch grip can be derived. If the diamond has the usual shape the rotating joints also move apart. If one corner of the 'diamond' forms a re-entrant, then when this is moved towards its opposite corner, the other two corners approach each other. In the former layout the web between the thumb and forefinger metacarpals is extended as in holding a glass. The latter system brings thumb and forefinger together in a nearly parallel fashion-as in holding a card-and may be more useful in the presence of finger contractures of various types.

\section{Control}

Control of these various devices is usually by some form of lever or button pressing action of which there are several types, some of which have been described in the Symposium on the Application of External Power to Prostheses and Splints (f. Bone ft Surg. 1965). The valve can be sited wherever the patient has a convenient movement; most valves require only 60 to $200 \mathrm{gm}$. through $0.5 \mathrm{~cm}$. or less.

The lever action can also of course be used to operate a potentiometer for systems employing electric motors. 
A proportional-response control system employing the muscle action potentials as signal has also been developed (Bottomley \& Cowell, 1964; Bottomley, 1965). This might also prove of use particularly when the residual muscle power of the arm, though present, is weak.

\section{REFERENCES}

Bottomley, A. H. (I965). Myoelectric control of powered prostheses. F. Bone ft Surg. 47B, No. 3, pp. 4II -415.

Bottomley, A. H. \& Cowell, T. K. (1964). An artificial hand controlled by the nerves. New Scientist, 2I, 668-670.

KINNIER Wilson, A. B. (I962). Design of a motorised elbow splint. Proceedings of the Symposium on Automatic Control in Prosthetics. Belgrade: Yugoslav Committee for Electronics and Automation.

KINNIER Wilson, A. B. (I965). Hendon pneumatic power units and controls for prostheses and splints. F. Bone $\mathcal{F}_{t}$ Surg. 47B, No. 3, pp. 435-44I.

Nickel, V. L. (I964). Investigation of externally powered orthotic devices. Final Report V.R.A. Grant R.D.-518. Attending Staff Association, Ranchos los Amigos Hospital, Downey, Calif., U.S.A.

SPENCER, W. A., ENGEN, T. J. \& GEDDES, L. A. (I964). Development of Externally powered upper extremity orthotics. Final Report V.R.A. Grant R.D.-542. Baylor University College of Medicine, Houston, Texas, U.S.A.

\section{BOOK REVIEW}

REHABILITATION OF THE SPINAL CORD INJURY PATIENT. By RosSIER, A. B., Documenta Geigy, Acta Clinica, 3, 1964, pp. I Io.

This monograph deals in detail with the scientific and clinical basis of the re-education of the paraplegic patient. Taught by doctor, nurse, physiotherapist and occupational therapist, he will have to learn much if he is to return to as normal a life as possible.

The care of his skin will be his duty, the proper functioning of the paralysed bladder and bowel will rely on his observation of individual rules. The training of remaining muscular power and physical skills will proceed in stages, guided by those experienced in assessing his potential.

The doctor-teacher's task is described in clear and well illustrated chapters. Outstanding are the outline of the re-education of the bladder and an original summary of the physical capabilities of patients with paraplegia at the various levels.

The considerable experience of the author acquired in Switzerland, France, England and the U.S.A. is apparent everywhere. The immediate treatment of the spinal injury and the re-education of the female bladder are not dealt with.

Throughout, this book shows evidence of wide reading and an optimism balanced by experience, the more authentic for the fact that this young chief of the new Centre for paraplegics in Geneva is a traumatic paraplegic himself, a shining example of successful rehabilitation.

L. Michaelis 